\title{
O DIREITO DO TRABALHO EM FACE DA NOVA CONSTITUIÇĀO (Aula inaugural do ano de 1988)
}

\author{
Octávio Bueno Magano \\ Titular do Departamento de Direito do Trabalho da Faculdade de \\ Direito da Universidade de São Paulo
}

\begin{abstract}
Resumo: O estudo ocupa-se com a análise dos direitos sociais no projeto de Constituição, conceituando-os e discutindo o problema de sua aplicabilidade.

Resumé: L'étude s'occupe avec l'analyse des droits sociaux dans le cadre du projet de Constitution, en les conceptuant et en discutant le problème de son aplicabilité.
\end{abstract}

Unitermos: Constituição; Direito do Trabalho; Direitos Sociais.

1. Direito do Trabalho é o conjunto de princípios, normas e instituições, que, incidindo sobre as relações do trabalho, visa à proteção do trabalhador e à melhoria da sua condição social.

Assim concebida, a disciplina divide-se em direito individual do trabalho, direito coletivo do trabalho, direito tutelar do trabalho, previdência e assistência social.

2. No Projeto de Constituição, em debate na Constituinte, observa-se que os três primeiros segmentos do Direito do Trabalho estão sendo tratados sob a rubrica de Direitos Sociais, ao passo que os dois últimos inserem-se no capítulo da "Seguridade Social", pertencente ao título, mais abrangente, denominado "Da Ordem Social"

3. A classificação apontada gera a necessidade de se definirem os direitos sociais, contrapondo-os, a seguir, aos conceitos de "ordem social" e "seguridade social"

Num sentido amplo, o Direito Social compreende necessariamente todos os ramos do Direito, porque o homem é um animal social: as relações jurídicas em que se envolve são necessariamente sociais. Numa tentativa de individualizar o Direito Social, já se asseverou que as suas normas diriam respeito à estrutura e ao funcionamento da sociedade ${ }^{(1)}$. Assim concebido seria algo seme-

(1) Hayek, F.A., Droit, législation et liberté, Paris, Presses Universitaires de France, 198 , p. 94. 
lhante ao Direito Constitucional, entendido como conjunto de regras sobre a estrutura do poder e suas funçōes ${ }^{(2)}$.

4. Em sentido estrito, já teve grande voga o conceito de que o Direito Social seria um "tertium genus", colocado entre o Direito Público e o Privado(3). Particularizar-se-ia pela sua natureza integrativa. Enquanto o Direito Público estabelece relações de subordinação e o Privado de coordenação, o Direito Social seria direito integrativo, quer dizer, de integração do homem dentro dos grupos e da sociedade, de cujos poderes participaria ${ }^{(4)}$.

Modernamente, caracteriza-se o Direito Social, como instrumento do Estado do Bem-Estar Social. Compreende, portanto, o conjunto de normas e instituições, fundadas no princípio da solidariedade ${ }^{(5)}$ e destinadas a promover $o$ bem-estar dos indivíduos integrantes de uma sociedade.

Devido à sua abrangência e heterogeneidade, a matéria respectiva não pode ser concebida como ramo específico do Direito ${ }^{(6)}$, adequando-se melhor à idéia de ordem social.

Ao que tudo indica foi essa a perspectiva em que se colocaram os ilustres membros da Comissão Provisória de Estudos Constitucionais, em cujo Projeto não se fala de direitos sociais mas exclusivamente de "ordem social"( (†)

5. A ordem social concebida como conjunto de normas e instituições destinadas à promoção do progresso social compreende os direitos dos trabalhadores (individual, coletivo, tutelar), a seguridade social (saúde, previdência, assistência), os chamados direitos culturais (educação, cultura, desporto, ciência, tecnologia, comunicação), as regras sobre meio ambiente, às relativas à família, à criança, aos adolescentes, aos idosos e aos índios.

Como se vê, a abrangência e a heterogeneidade da matéria integrante da

(2) Ferreira Filho, Manoel Gonçalves, Curso de Direito Constitucional, São Paulo, Saraiva, 1979, p. 20.

(3) Cesarino Jr., A.F., Direito Social, São Paulo, LTr, 1980, p. 61.

(4) Gurvitch, L’idée du droit social, Paris,S irey, 1932, p. 16/23.

(5) Siches, Luis Recasens, Tratado General de Filosofia del Derecho, Mexico, Porrua, 1970 , p. 602.

(6) Szabo, Imre, Les dimensions internationales des droits des l'homme, Unesco, 1979, p. 20.

(7) Moraes Filho, Evaristo, A ordem social num novo texto constitucional, São Paulo, LTr, p. 11. 
ordem social são fatores excludentes de sua insersão em ramo específico do Direito.

6. Com a ordem social não se confundem nem os direitos democráticos nem os direitos e garantias individuais. À primeira espécie pertencem as regras tendentes a assegurar a participação de interessados na estrutura e funcionamento de entidades estatais, parestatais ou outras instituiçōes de relevância social, como as empresas e os sindicatos ${ }^{(8)}$. A segunda espécie é composta de regras destinadas a defender, de modo institucionalizado, os direitos da pessoa humana contra agressōes e abusos por parte de outras pessoas, notadamente as autoridades públicas $^{(9)}$.

Não há confundir os chamados direitos sociais com os direitos democráticos porque enquanto estes giram em torno da idéia de participação, aqueles têm como escopo a melhoria de condições sociais.

Menor ainda é a possibilidade de se confundirem os chamados direitos sociais com os direitos e garantias individuais pelas três principais razōes abaixo aduzidas: primeira, porque estes surgiram para coibir abusos da autoridade, atingindo o apogeu com o predomínio do individualismo liberal (Bills of rights are for the most part reactions against evils of the past rather than promisses for the future $)^{(10)}$, enquanto aqueles forjaram-se para a promoção dos pobres e vieram à tona com o industrialismo do século XIX, explicitando-se em algumas constituições do tempo da Primeira Grande Guerra, como a mexicana e a de Weimar, e atingindo o apogeu com o término da Segunda Grande Guerra; segunda, porque as garantias individuais exigem abstenção por parte do Estado, ao passo que os direitos sociais pressupōem da parte desta atividade progressi$\mathrm{va}^{(11)}$, terceira, porque os direitos individuais correlacionam-se com claras e precisas obrigações de não fazer por parte do Estado e outras pessoas, ao passo que as regras componentes do chamado Direito Social traduzem-se apenas em padrōes de conduta norteadores da atividade do Estado ${ }^{(12)}$.

A última distinção bem se ilustra com os exemplos do Pacto Internacional sobre Direitos Civis e Políticos e o Pacto Internacional sobre Direitos Econômicos, Sociais e Culturais, celebrados sobre os auspícios da ONU, em 1966.

(8) Siches, ob. cit., p. 601.

(9) Idem, p. 601.

(10) Tresolini, Rocco J., N.Y., Macmillan Co., 1959, p. 346.

(11) Siches, ob. cit., p. 602. (12) Van Boven, T.C., Les dimensions internationales des droits de l'homme, Unesco,
p. 53 . 
Enquanto as regras integrantes do primeiro se mostram suscetíveis de aplicação e reconhecimento judicial imediatos, as componentes do segundo devem ser postas em prática progressivamente, não sendo judicialmente exigíveis ${ }^{(13)}$. Com efeito, no Pacto sobre Direitos Civis e Políticos, declara-se enfaticamente: as partes signatárias "obrigam-se a respeitar e a garantir a todos os indivíduos (...) os direitos reconhecidos neste Pacto..."(14). Já, no Pacto sobre Direitos Sociais, afirma-se apenas que as partes signatárias obrigam-se "a agir (...), tendo em vista assegurar progressivamente o pleno exercício dos direitos reconhecidos neste Pacto..."(15). No primeiro caso, trata-se de respeitar e garantir algo já existente, enquanto, no segundo, cuida-se tão-somente de agir progressivamente para a implantação de nova ordem reconhecida desde logo como desejável.

Convém sublinhar que a distinção aqui assinalăda reflete-se também na Convenção Européia dos Direitos do Homem, quando comparada com a Carta Social Européia ${ }^{(16)}$. Na Convenção Americana sobre Direitos Humanos, de novembro de 1969, as duas matérias são tratadas em capítulos distintos e, enquanto, dos direitos civis e políticos, se diz que devem ser reconhecidos, dos direitos econômicos, sociais e culturais, afirma-se, exclusivamente, que hão de ter desenvolvimento progressivo ${ }^{(17)}$.

7. Do exposto, infere-se que o Projeto em tramitação na Constituinte ressente-se de grave falha de sistematização. A matéria ali tratada sob a rubrica de direitos sociais possui vinculação muito mais estreita com a disciplinada no título "Da ordem social", do que com a dos direitos e garantias individuais. $\mathrm{Na}$ verdade, constitui aquela, juntamente com a Previdência Social, a Saúde e a Assistência Social o próprio cerne da ordem social. Não há como separá-las. Contudo, se houvessem de ser desagregadas, a que deveria aparecer com o signo de direitos sociais seria a pertinente à previdência, à assistência e à saúde, reunindo-se os tópicos relativos ao direito individual do trabalho, direito coletivo do trabalho e direito tutelar do trabalho, sob o rótulo de direitos trabalhistas. Outra alternativa, inspirada nos documentos de nível internacional, acima mencionados, seria a de se tratar de direitos e garantias individuais, sob a inscrição direitos civis e políticos, e das demais regras aqui assinaladas, sob o dístico, di-

(13) Idem, p. 54.

(14) Rangel, Vicente Marotta, Direito e Relações Internacionais, São Paulo, RT, 1981, p. 357 .

(15) Idem, p. 346.

(16) Vak, Karel, Les dimensions internationales des droits des l'homme, Unesco, p. 536 e 593.

(17) Rangel, ob. cit., p. 381 e 388. 
reitos sociais e culturais. O critério extravagante adotado pela Comissão de Sistematização é que não pode prevalecer.

8. De um ponto de vista prático, o que se não pode admitir sem relutância é que se queira atribuir efeito imediato a normas constantes do capítulo denominado "Dos direitos sociais", de caráter meramente programático, como as que tratam do seguro desemprego; da participação nos lucros das empresas; da redução de riscos inerentes ao trabalho; da assistência gratuita a filhos e dependentes, em creches e pré-escolas, etc. A natureza dos apontados direitos implica, quase sempre, a prévia montagem de estruturas em que se apoiem e por isso a sua realização prática só pode ocorrer progressivamente, nunca de imediato. Não obstante, os constituintes - alguns certamente por inadvertência - aprovaram texto onde se lê o seguinte: "As normas definidoras dos direitos e garantias fundamentais têm aplicação imediata". Assim procedendo ignoraram as lições mais modernas da doutrina, no sentido de atribuir eficácia a todas as normas constitucionais, mas com a ressalva de que se trata de eficácia gradativa ${ }^{(18)}$ Como acentua Jorge Miranda, da Universidade de Lisboa, "as normas programáticas são de aplicação diferida, e não de aplicação ou execução imediata"(19), o que não briga com a juridicidade delas, "porque a dimensão prospectiva é também uma dimensão do ordenamento jurídico..."(20).

9. Tendo em vista os segmentos de que se compõe o Direito do Trabalho, inicialmente especificados, cumpre agora examinar como vêm sendo eles disciplinados pelos Constituintes.

No âmbito do direito individual do trabalho, a questão mais empolgante é a da eliminação da despedida arbitrária, por eles agasalhada, nestes termos: "relação de emprego protegida contra despedida arbitrária ou sem justa causa, nos termos de lei complementar, que preverá indenização compensatória, dentre outros direitos"

Como se vê, não prevaleceu, no seio da Assembléia Constituinte, nem a posição daqueles que queriam abroquelar-se ao direito potestativo de despedir, nem a da facção radical, favorável à estabilidade.

Sagrou-se vitoriosa a tese da eliminação da despedida arbitrária ou sem justa causa, com o que o Brasil acertou o passo com o padrão estabelecido pela

(18) Silva, José Afonso, Aplicabilidade das Normas Constitucionais, São Paulo, RT, 1982, p. 72.

(19) Manual de Direito Constitucional, Coimbra, Coimbra Editora, 1983, Tomo II, p. 218.

(20) Idem, p. 219. 
Convenção 158 , da Organização Internacional do Trabalho, refletido na maioria dos sistemas legislativos do mundo ocidental.

Vale dizer que, a partir de agora, o empregador não poderá mais despedir empregado por mero capricho. Poderá, porém, fazê-lo quando fundado em razão objetiva.

Como no texto a objetividade em causa não se correlaciona apenas à inexistência de justa causa mas também à configuração de arbitrariedade, impõe-se a conclusão de que o empregador poderá despedir o empregado que incidir em falta grave (justa causa), mas igualmente quanto estiver confrontado com fatos impeditivos do bom funcionamento da empresa, tais como fato econômico relevante e motivos de ordem técnica. Não se patenteando qualquer das apontadas razões objetivas justificadoras da despedida, a sanção imposta ao empregador não será a reintegração do empregado despedido, mas o pagamento de indenização. Contudo, tendo em vista o teor do texto aprovado, poderá o legislador, atentando para situações específicas, cuidar da formulação de outros direitos, tais como, por exemplo, o da reintegração para empregados portadores de representação sindical.

No campo do direito coletivo do trabalho, a questão obviamente mais significativa é a da unidade ou a do pluralismo sindical. Não há titubear na escolha da segunda alternativa, porque o monopólio de cúpulas sindicais é tão nefasto quanto o exclusivismo político. Como o texto em tramitação na Assembléia Constituinte aponta o pluralismo político como um dos fundamentos do Estado democrático, cumpria à mesma Assembléia, coerentemente, adotar o pluralismo sindical como outro de seus sustentáculos. E tanto mais imperiosamente deveria assim proceder quanto é certo existir crescente interpenetração entre o político e o sindical ${ }^{(21)}$ Numa democracia pluralista, os grupos profissionais tendem a se tornar peças cada vez mais importantes no equilíbrio do sistema não só por serem fatores de limitação do poder estatal ${ }^{(22)}$ senão também por se apresentarem como agentes promotores do interesse público, como sucede quando entabulam pactos sociais; participam da gestão de entidades públicas; ou, simplesmente, ingressam com ação de inconstitucionalidade, perante o Supremo Tribunal Federal, segundo se prevê no Projeto em tramitação. O exercício das apontadas funçōes políticas não deve ficar sujeito a nenhum monopólio de cúpulas, ao contrário, numa democracia, é mister que seja acessível a todas as facções de que se compõe, a sociedade civil. Por outro lado, numa

(21) Fois, Sergio, Sindicati e sistema político, Milano, Giuffrè, 1978. Vide também Sagardoy, Juan A., Relaciones del trabajo u estructuras políticas, Madrid, Instituto de Estudios Laborales y de la Seguridade Social, 1984.

(22) Loewenstein, Karl, Political Power \& Governmental Process, Chicago, The University of Chicago Press, 1965, p. 344. 
democracia, os sindicatos devem possuir autonomia, o que significa manteremse com recursos próprios. Nesse quadro, não há lugar para a continuidade da contribuição sindical compulsória, conseqüência de, nos regimes autoritários, exercerem funções delegadas do poder público. Ainda na área do direito coletivo, é mister dar realce à função atribuída à convenção coletiva, que, até aqui, via de regra, só era apta a estabelecer condições mais propícias ao trabalhador, mas que, a partir do novo texto constitucional, poderá agasalhar condições "in pejus".

$\mathrm{Na}$ esfera do direito tutelar do trabalho, há cinco tópicos merecedores de atenção especial. O primeiro diz respeito ao acidente do trabalho, disciplinado como encargo de responsabilidade do empregador. Não há dúvida de que este deve ter participação no custeio respectivo, a fim de se interessar pela eliminação de condições perigosas geradoras de infortúnio. Contudo, a responsabilidade primacial, pela sua manutenção, deveria ser da Previdência Social, tal como ocorre no presente, por ser de curso universal o entendimento de que o acidente do trabalho constitui risco social, a ser coberto pelas prestações da referida instituição. $\mathrm{O}$ segundo tópico a realçar-se é concernente à licença paternidade de oito dias, benefício que encontra precedente na lei italiana $n^{\circ} 903$, de 9 de dezembro de 1977, na qual se confere alternativamente aos dois genitores o direito de se ausentarem do trabalho para cuidarem dos filhos. Segue-se o item relativo à prescrição, correspondente, em princípio, ao prazo de cinco anos. Assim, se o direito do trabalhador é violado em 1983, poderá reclamar contra a violação até 1988. Na hipótese específica de rescisão contratual, o prazo contar-se-á da data em que esta ocorrer. Assim, se a violação verificou-se em 1983, tendo sido o empregado despedido em 1987, poderá impugná-la até 1989. De grande relevo mostra-se igualmente a regra sobre piso salarial proporcional à extensão e à complexidade do trabalho, o que significará a possibilidade de tratamento legal mais favorável para determinadas categorias profissionais. Por último, é preciso considerar a jornada de trabalho que continua a ser de oito horas. $\mathrm{O}$ módulo hebdomadário foi, porém, diminuído para 44 horas semanais. Mais importante, todavia, é a imposição da jornada máxima de seis horas, para o trabalho realizado em turnos ininterruptos, o que vai certamente determinar a alteração dos turnos de revezamento de três para quatro, com conseqüente aumento de ônus para os empregadores.

No que concerne à Previdência Social, convém, antes de mais nada, indicar o seu significado, a saber, instituição pública, cuja finalidade é a de assegurar a renda do trabalhador, quando esta estiver diminuída ou extinta, em virtude de risco social. O campo próprio de incidência da Previdência é o dos trabalhadores subordinados; o seu funcionamento condiciona-se à ocorrência de riscos sociais favoráveis ou adversos, considerados como tais, a morte, a invalidez, a doença, a velhice, a maternidade, a família numerosa, o acidente do trabalho, $o$ desemprego, a reclusão do chefe de família. $\mathrm{Na}$ legislação ordinária brasileira, já se ultrapassaram os limites aqui apontados. Estendeu-se o campo de incidên- 
cia da Previdência Social, a fím de que passasse a se aplicar também a trabalhadores autônomos, avulsos, eventuais, temporários, a estudantes e até a empregadores. Ampliaram-se as suas prestações, incluindo-se no rol respectivo não só a aposentadoria por tempo de serviço, que não possui natureza previdenciária, mas ainda a assistência médica, farmacêutica e odontológica; a assistência complementar e a assistência reeducativa, que são, como os nomes indicam, prestações assistenciais e não previdenciárias. Como se vê, o legislador ordinário brasileiro converteu a Previdência Social numa instituição extremamente aparatosa, já atingindo as raias da segurança social. Mas isso apenas no papel. Toda gente conhece a precariedade dos seus programas assistenciais, a exigüidade dos benefícios por ela oferecidos e a lentidão com que se processam. Por isso, vem logo a talho a indagação: não teria sido melhor ao invés de tanta expansão, qualidade e efetividade das prestações dela provenientes?

No que respeita à assistência social, inserida ao longo do tempo, no corpo da previdência social, o menos que se pode dela dizer é que é vasqueira e, além disso, salvo exceções, de baixa qualidade.

Agora, o que se pretende, no âmbito da Assembléia Constituinte, é o conúbio da ineficácia com o disparate, ou seja, o acoplamento da previdência social com a assistência social, ampliadas ambas até os limites máximos de suas potencialidades. O que se tenciona implantar no Brasil é uma instituição taumatúrgica, denominada arrevezadamente de "seguridade social" e destinada a liberar o homem de toda e qualquer necessidade. Sim, porque a "seguridade social" é necessariamente universal. Não fica condicionada à configuração de determinados riscos previdenciários, mas se estende a toda e qualquer situação de dificuldade. Por outro lado, sendo universal, não se restringe a trabalhadores, mas abrange toda a população do país.

Toda gente sabe que instituição, assim aparatosa, é de difícil implantação. No Brasil, é duvidoso que mesmo sistemas simples de previdência e de assistência social possam funcionar eficazmente. $E$ isso devido a duas precariedades que nos são inerentes: escassez de recursos e população ativa reduzida em comparação à inativa. Sob esse último aspecto, cumpre assinalar que a população ativa representa um terço apenas do total, prevalecendo, nos seus desdobramentos, a faixa etária entre dez e quatorze anos de idade ${ }^{(23)}$.

10. No seu conjunto, o texto constitucional que se está votando mostra-se com grandes falhas de sistematização, excessivamente minucioso e, sob certos aspectos, fantasioso, o que faz incidir nesta crítica de Huxley: "no reform is

(23) Ministério do Trabalho, Indicadores Sócio-Econômicos, 1987. 
likely to achieve the results intended unless it is not only well intentioned, but also opportune"(24).

Contudo, as constituições dependem muito menos dos que a elaboram do que dos que as aplicam. A fé que deposito na juventude me faz crer que a nova Constituição venha a ser aplicada de modo construtivo, equilibradamente, com engenho e arte, tendo em vista as exigências do país. São Paulo, março de 1988

(24) Huxley, Aldous, Ends and Means, London, Harper \& Brothers, 1937, p. 31. São Paulo, março de 1988. 